Revista Brasileira de Agricultura Irrigada v.13, nº.5, p. 3691 - 3702, 2019

ISSN 1982-7679 (On-line)

Fortaleza, CE, INOVAGRI - http://www.inovagri.org.br

DOI: $10.7127 /$ rbai.v13n5001140

Protocolo 1140.19 - 09/04/2020 Aprovado em 09/04/2020

\title{
ESTUDO DE VIABILIDADE DO USO DE ENERGIA EÓLICA PARA IRRIGAÇÃO DA BANANICULTURA DO CEARÁ
}

\author{
Aline Castro Praciano ${ }^{1}$, Adryane Gorayeb ${ }^{2}$, Leonardo de Almeida Monteiro ${ }^{3}$
}

\begin{abstract}
RESUMO
A alta qualidade de vento do estado do Ceará torna a geração de energia eólica muito atrativa, e por isso, vem recebendo importantes subsídios do governo brasileiro. O Ceará está localizado na região Nordeste do Brasil, com clima predominante semiárido, o que torna o uso de irrigação na agricultura algo indispensável para obtenção de uma produção contínua e mais eficiente. A distribuição de energia elétrica da sede da unidade rural até a área de produção é muito onerosa e por diversas vezes inviável financeiramente para o produtor rural, impossibilitando a implantação dos sistemas de irrigação. Diante desse cenário, o trabalho tem por objetivo avaliar a viabilidade do uso de energia eólica nos setores de produção de banana no Ceará, com o intuito de utilizá-la para atender a demanda dos sistemas de irrigação. Para isso, utilizou-se como metodologia, ferramentas de geoprocessamento de dados do software QGIS 2.18. Obteve-se como resultado, que dos 184 municípios do estado com uma produção mais expressiva (em pequena escala), 31 apresentaram viabilidade para a geração de energia eólica e 26 não apresentam potencialidade para geração de energia eólica.
\end{abstract}

Palavras-Chave: energia renovável; banana; mapas.

\section{FEASIBILITY STUDY ON THE USE OF WIND POWER FOR IRRIGATION OF CEARÁ BANANICULTURE}

\begin{abstract}
The state of Ceará has a high potential of renewable electric energy production, due to the high quality of the winds being in this Brazilian state, for that reason it segment has been receiving important subsidies from the Brazilian Government. The state of Ceará is located in the Northeast region of Brazil, with a predominant semi-arid climate. Facing the agricultural production of the region,

\footnotetext{
${ }^{1}$ Mestre em Engenharia Agrícola, Departamento de Engenharia Agrícola, Universidade Federal do Ceará, Fortaleza, Brasil, Centro de Ciências Agrárias - CCA/UFC, Bloco 804 - Departamento de Eng. Agrícola CEP:60 455-760, alinecatro.praciano@gmail.com

${ }^{2}$ Professora Doutora, Departamento de Geografia, Universidade Federal do Ceará, Fortaleza, Brasil, Centro de Ciência, Bloco 911 - Departamento de Geografia CEP 60 440-900. gorayeb@ufc.br

${ }^{3}$ Professor Doutor, Departamento de Engenharia Agrícola, Universidade Federal do Ceará, Fortaleza, Brasil, Centro de Ciências Agrárias - CCA/UFC, Bloco 804 - Departamento de Eng. Agrícola CEP:60 455-760, aiveca@ufc.br.
} 
irrigation management is indispensable to obtain a continuous and efficient crop production. The transmission of electricity from the headquarters of the rural unit to the production area is very onerous and often not financially viable for rural producers, making it impossible to implement irrigation systems in areas suitable for this use. Therefore, this study aims to assess the feasibility of using wind energy in the banana production sector in the state of Ceará, in order to use it to fulfill the demand of irrigation systems in this region. The geoprocessing tools of the QGIS 2.18 software were used as methodology. As a result, of the 184 municipalities in the state with a more expressive production, 31 showed viability for wind power generation and 26 did not have potential for wind power generation.

Keywords: renewable energy; banana; maps

\section{INTRODUÇÃO}

A banana é a fruta mais consumida no mundo inteiro, principalmente em regiões tropicais (BRASIL, 2018). Segundo a FAO (2017), o Brasil possui aproximadamente 500 mil hectares de área cultivada para a produção de banana, com uma produção de mais de 7 milhões de toneladas. Praticamente toda a produção é para consumo interno, haja vista, que apenas $1 \%$ da produção é exportado. No Ceará a produção de bananas está presente em todos os perímetros irrigados, o Estado possui 39.140 ha de plantio de banana, com uma produção total de 323.840 toneladas da fruta em 2017, o município com maior produção é Missão Velha com 31.839 toneladas (IBGE, 2018).

Atualmente, no Brasil a energia hidroelétrica representa $66 \%$ da matriz elétrica do País (ANEEL, 2017). A escassez de chuvas nos últimos anos, gerou baixos níveis de água nos reservatórios, provocando uma grave crise na geração de energia do País. Fato que pôs em risco a segurança da distribuição de energia elétrica a população, causando inclusive racionamento de energia e acionamento de termelétricas, tornando o custo da energia para o consumidor final mais oneroso (SEEG, 2017).

No Nordeste, cerca de $74 \%$ da energia consumida foi proveniente de energia eólica. Do ano de 2017 para o de 2018 houve um crescimento na geração de energia eólica na região nordeste de $17 \%$, o estado do Ceará destaca-se como um dos cinco estados com maior geração no período de 2018 (ABEEOLICA, 2018). A alta qualidade de vento do estado do Ceará torna a geração de energia eólica muito atrativa, e por isso, está vem recebendo importantes subsídios do governo brasileiro (GWEC, 2017).

O Ceará está localizado na região Nordeste do Brasil, com clima predominantemente semiárido, que é caracterizado por ser seco e quente, com pequena variação de temperatura durante o ano, variando entre $25^{\circ} \mathrm{C}$ e $28{ }^{\circ} \mathrm{C}$, baixo volume de precipitação, com índice pluviométrico médio anual de $750 \mathrm{~mm}$, concentrados entre os meses de janeiro e maio (PAGANO et al., 2013). Diante desse cenário o uso de irrigação na agricultura é algo indispensável para obtenção de alta produtividade e aliada a uma produção contínua.

O Programa Social Luz para Todos, criado em 2003, tem como principal objetivo levar energia elétrica a pessoas de baixa renda. Atualmente, cerca de $98 \%$ da população já possui energia elétrica em suas residências, mas ainda existe mais de 1 milhão de famílias excluídas do acesso à energia elétrica no País, grande parte dessa população está sediada em áreas rurais (MME, 2018). As avaliações realizadas pelo programa luz para todos após 10 anos de implantação, afirma que o acesso à energia elétrica melhorou a produção agrícola em aproximadamente $31 \%$, melhorando a renda familiar em 41\% (MME, 2013). Porém, este Programa do Governo não cobre os custos de distribuição da energia elétrica da sede da unidade rural até a área de produção.

O sensoriamento remoto é uma ferramenta eficiente que permite atender as necessidades de monitoramento de vários aspectos da agricultura, mas deve ser feito de forma racial e otimizada visando atender preocupações de várias ordens (SANCHES, 
2016). Nesse contexto, objetivou-se avaliar a viabilidade do uso de energia eólica para atender a demanda de sistemas de irrigação em áreas de produção de banana no estado do Ceará utilizando como metodologia ferramentas de geoprocessamento.

\section{MATERIAL E MÉTODOS}

\section{Área de Estudo}

O Ceará está situado no norte da Região Nordeste e tem por limites o Oceano Atlântico a norte e nordeste, Rio Grande do Norte e Paraíba a leste, Pernambuco ao sul e Piauí a oeste. Com clima predominante semiárido, que é caracterizado por ser seco e quente, com pequena variação de temperatura durante o ano, variando entre $25^{\circ} \mathrm{C}$ e $28{ }^{\circ} \mathrm{C}$, baixo volume de precipitação, com índice pluviométrico médio anual de $750 \mathrm{~mm}$, concentrados entre os meses de janeiro e maio (PAGANO et al., 2013). Sua área total é de $148.887,633 \mathrm{~km}^{2}$, tornando-o o $17^{\circ}$ estado em termos de território e a $16^{\mathrm{a}}$ maior economia do País. A população estimada do estado é de 9.020.460 de habitantes (IBGE, 2017), ocupando a oitava colocação entre as unidades federativas mais populosas do País.

\section{Etapas Metodológicas}

Para avaliar o potencial eólico do estado do Ceará, utilizou-se o mapa de potencial eólico anual do Atlas de potencial eólico do estado do Ceará (SEINFRA, 2001), como mostra a Figura 1. O mapa foi georreferenciado no software QGIS 2.18, posteriormente, realizou-se classificação supervisionada pelo método Máxima Verossimilhança, adotando-se nessa classificação 6 clusters, que representam seis classes de vento, que variam de 10 a 3,5 $\mathrm{ms}^{-1}$.

Com o raster gerado foi obtido um mapa com 6 classes de vento e outro com apenas 2 classes, a primeira mostra o território cearense com viabilidade de geração de energia eólica e a outra com as áreas de inviabilidades, adotando como velocidade inicial para geração de energia eólica $7 \mathrm{~m} \mathrm{~s}^{-1}$ (ANEEL, 2005).

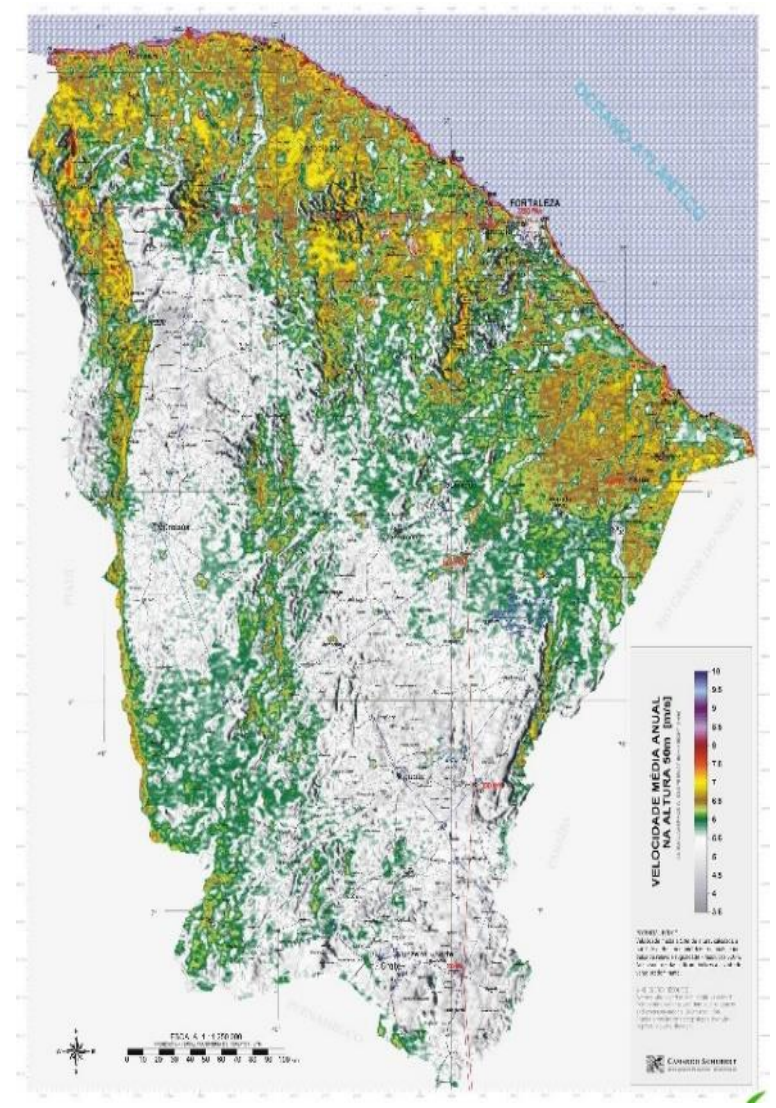

Figura 1. Mapa de Potencial Eólico do Ceará

A banana é produzida predominantemente na Ásia, América Latina e África (FAO, 2018). A temperatura ótima para o cultivo comercial de bananas fica na faixa de $15{ }^{\circ} \mathrm{C}$ a $35^{\circ} \mathrm{C}$, a bananeira é uma planta exigente consumo de água, devido a morfologia e hidratação de seus tecidos, a maioria das produções de banana estão associadas a uma oferta total anual de $1.900 \mathrm{~mm}$, bem distribuídas no decorrer do ano, ou seja, $5 \mathrm{~mm}$ ao dia (EMBRAPA, 2018). O cultivo de bananeiras requer alta luminosidade, nessas condições o período para que o cacho atinja o ponto de corte é de 80 a 90 dias após a emissão, em regiões de baixa luminosidade esse período pode aumentar para 85 a 112 dias, a atividade fotossintética é aumentada quando a iluminação se encontra na faixa de 2.000 a 10.00 lux. As bananeiras toleram ventos de até $40 \mathrm{~km} \mathrm{~h}^{-1}$, velocidades entre 40 e $55 \mathrm{~km} \mathrm{~h}^{-1}$ produzem danos moderados, como por exemplo o desprendimento total ou parcial da planta, causando perdas de $20 \%$ a $30 \%$ produção total, porém variedades de porte 
Praciano et al.

baixo podem suportar ventos de até $70 \mathrm{~km} \mathrm{~h}^{-1}$, como é o caso da variedade nanica (EMBRAPA, 2018). Segundo a FAO (2018), a banana requer um suprimento amplo e frequente de água, déficits hídricos afetam negativamente o crescimento e a produtividade das lavouras. $\mathrm{O}$ fornecimento regular de água sob irrigação durante a estação de crescimento total, em comparação com a produção de sequeiro, com diferenças sazonais no abastecimento de água, produz plantas mais altas, com maior área foliar, e resulta em
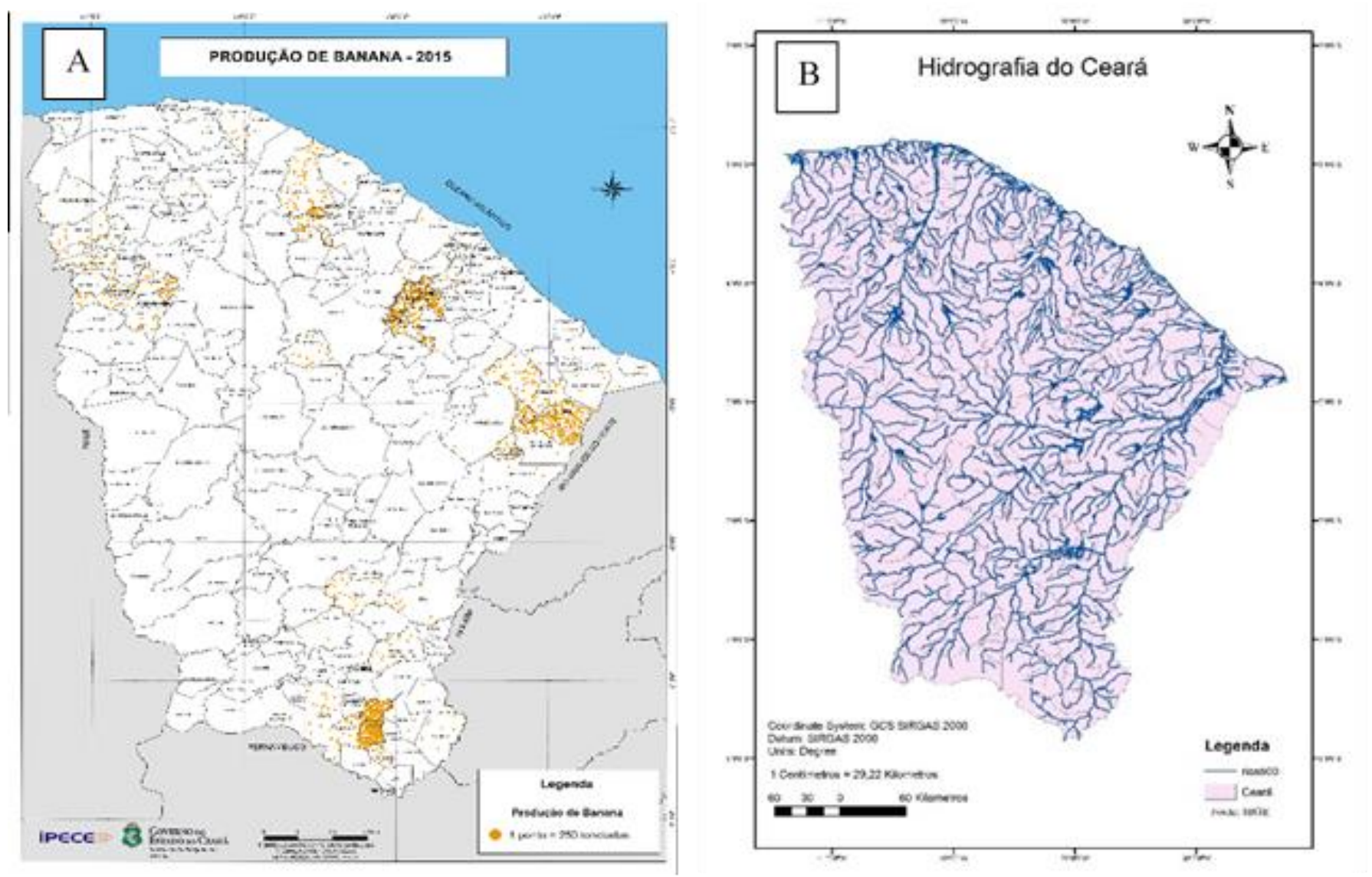

Figura 2. A - Produção de Banana - 2015; B - Hidrografia do Ceará

Para avaliar a viabilidade de irrigação utilizou-se o shapefile da hidrografia do Ceará, disponibilizado pelo IBGE (2014) (Figura 2B).

As três camadas criadas foram cruzadas e foi gerado um mapa onde é possível avaliar através da intercessão das informações as áreas com potencial para geração de energia eólica. emissão de frutos mais cedo e maiores rendimentos.

As áreas de produção de banana no Ceará foram identificadas a partir do mapa de produção de banana no Ceará do ano de 2015 (Figura 2A), disponibilizado pelo Instituto de Pesquisa e Estratégia Econômica - IPECE. O mapa foi georreferenciado e gerado um novo shapefile de pontos no software QGIS 2.18, onde cada ponto representa a produção de 250 toneladas de banana.

\section{RESULTADOS E DISCUSSÃO}

Após realizar a classificação supervisionada na Figura 1, foi gerado um shapfile com o potencial eólico anual classificado com 6 clusters. A Figura 3 expõe as potencialidades do território cearense para geração de energia eólica. 


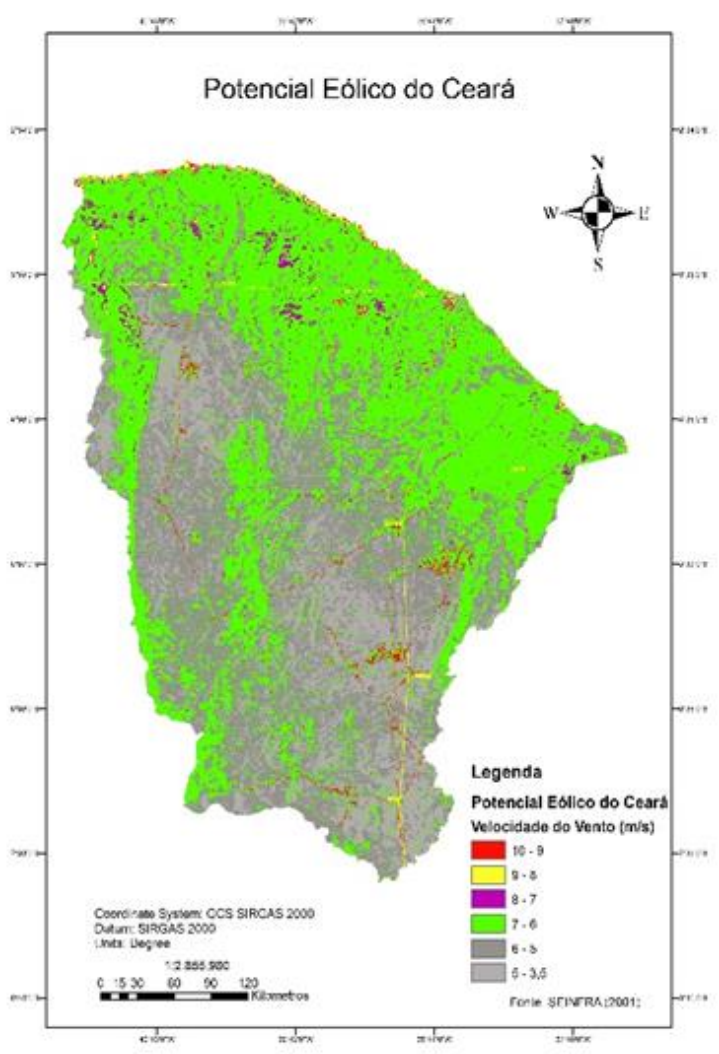

Figura 3. Mapa de potencial eólico do Ceará.

Segundo a ANEEL (2005), a geração de energia eólica só viável economicamente em regiões com velocidades medias superiores a 7 $\mathrm{m} \mathrm{s}^{-1}$. Com base nessa informação, gerou-se a partir da Figura 3 um mapa dois clusters, o primeiro com áreas viáveis para a geração de energia eólica e a segunda com áreas inviáveis para a geração de energia eólica, a Figura 4 apresenta os territórios com o território com potencial para gerar energia eólica. Segundo a Organização Mundial de Meteorologia, em apenas $13 \%$ da superfície terrestre o vento apresenta velocidade média igual ou superior a $7 \mathrm{~m} \mathrm{~s}^{-1}$, a uma altura de $50 \mathrm{~m}$.

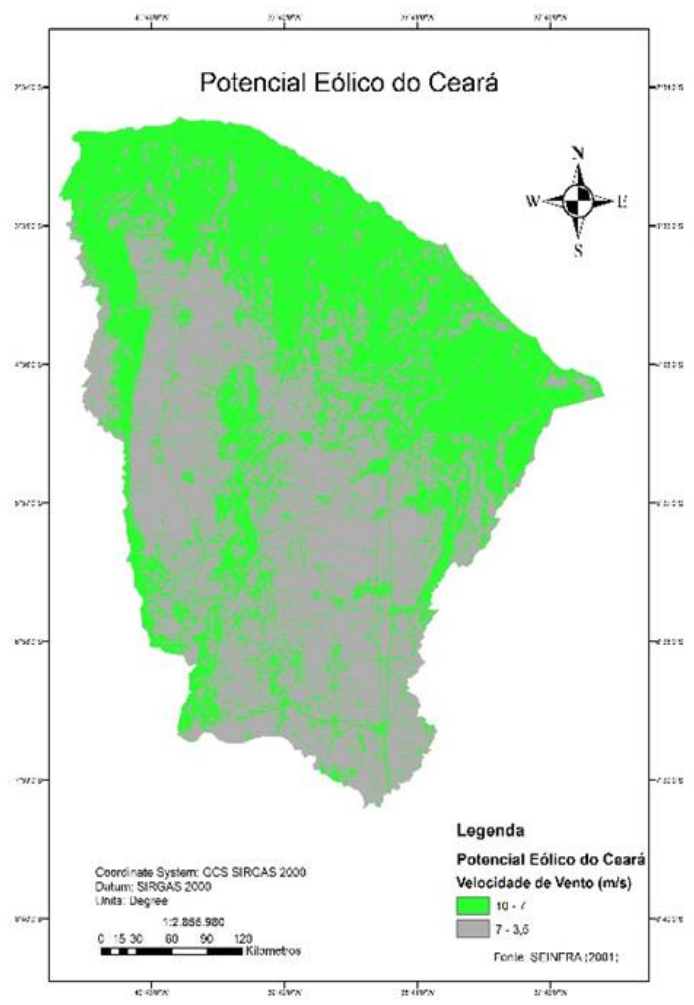

Figura 4. Mapa de viabilidade de geração de energia eólica.

Cruzando o raster criado com o potencial de energia eólica (Figuras 3 e 4) e a camada vetorial de pontos que representa a produção de banana no Ceará, temos as áreas de produção de banana onde existe viabilidade para geração de energia eólica, como é possível observar nas Figuras 5A e 5B 

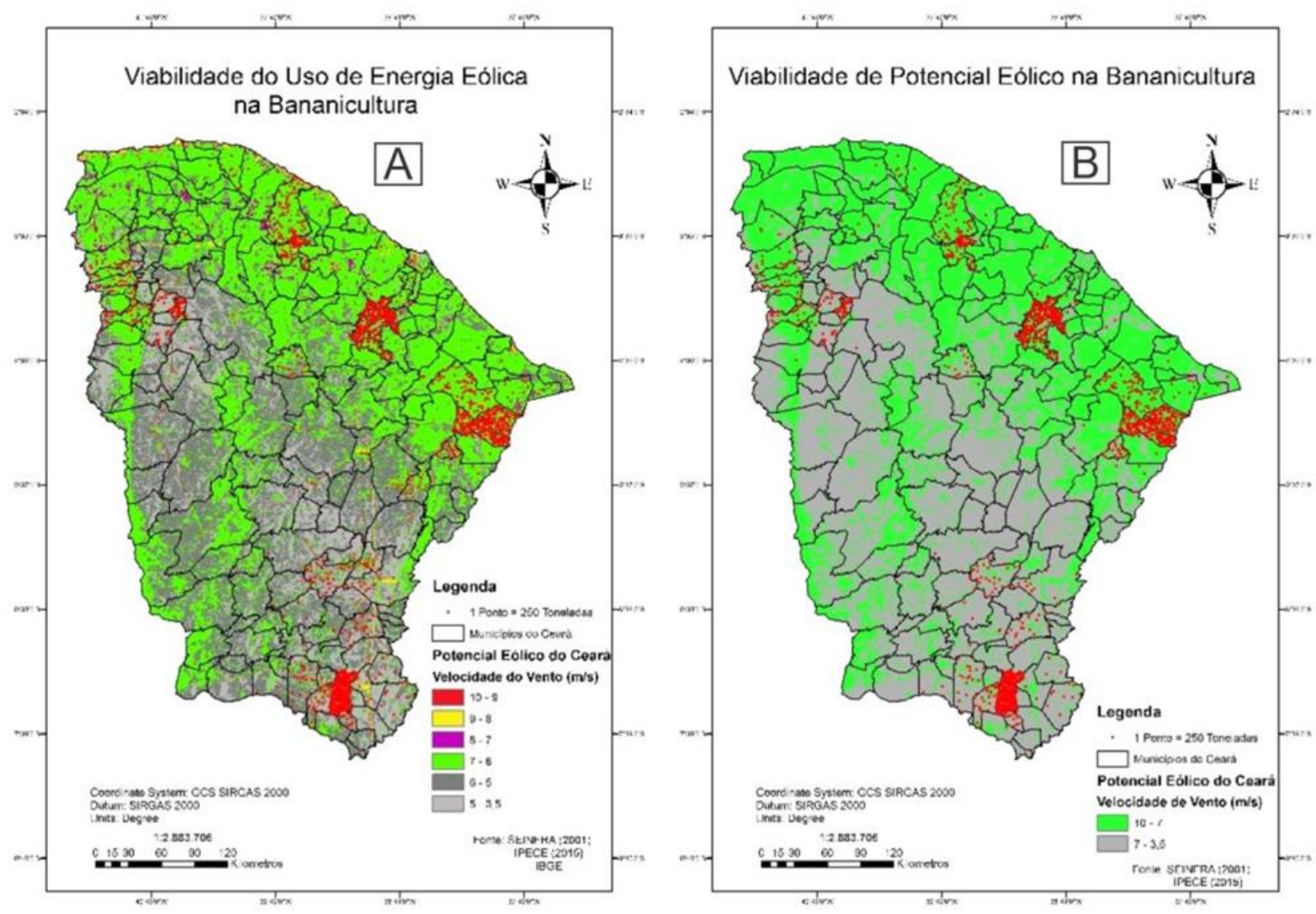

Figura 5. Mapa de viabilidade do uso de energia eólica na bananicultura do Ceará.

Avaliando as informações expressas na Figura 6 observa-se que existem diversas regiões produtoras de banana que não possuem viabilidade para geração de energia eólica, esses municípios estão localizados principalmente nas mesorregiões do Noroeste Cearense, Centro-Sul Cearense e Sul Cearense, como destaca a Figura 7.

A mesorregião Noroeste possui municípios produtores de banana com viabilidade e inviabilidade para geração de energia eólica, nessa última condição destacam-se os municípios de Coreaú, Ipu, Pires Ferreira, Santa Quitéria, Frecheirinha, Varjota, Reriutaba e Sobral, sendo os três últimos municípios citados, os municípios com maior produtividade da mesorregião sem viabilidade para gerar energia eólica.

A mesorregião Centro-Sul Cearense demostra baixo potencial para geração de energia eólica praticamente em sua totalidade, a mesorregião possui sete municípios produtores de banana, que são os seguintes: Acopiara, Lavras da Mangabeira, Icó, Carius, Iguatu e Várzea Alegre, em termos de produção destacam-se os dois últimos municípios citados.

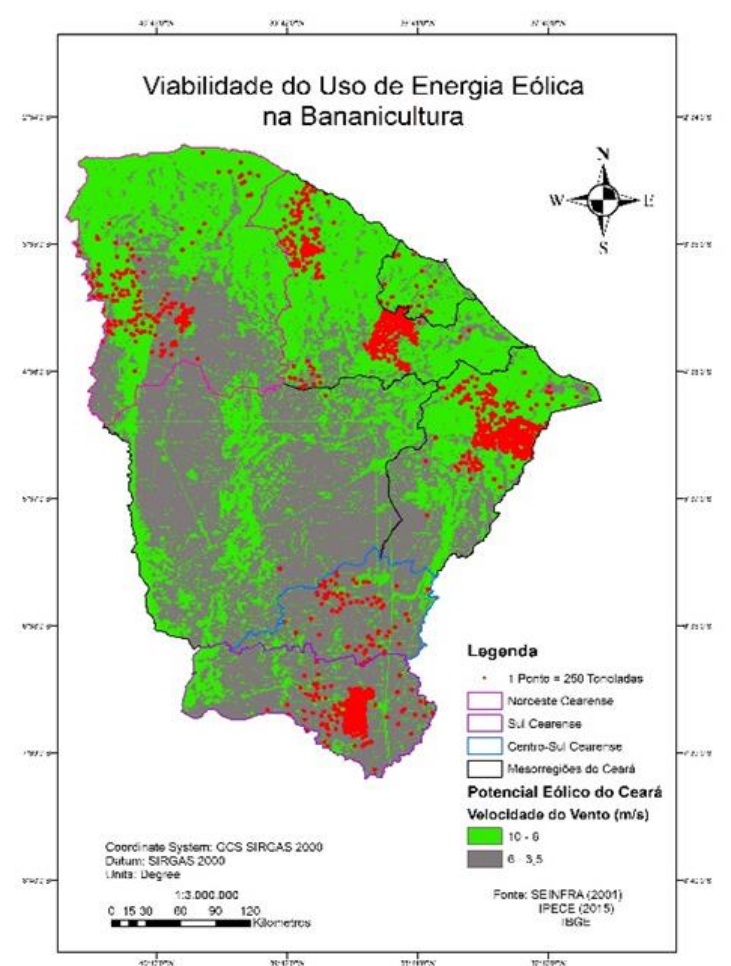

Figura 7. Destaque das mesorregiões com municípios produtores de banana sem viabilidade para geração de energia eólica. 
A mesorregião Sul Cearense apresenta condições de vento semelhantes a mesorregião Centro-Sul Cearense, com ventos de baixa velocidade o potencial eólico inviabiliza a geração de energia eólica nessa região, porém os municípios com maior produção de bananas no estado estão localizados nessa mesorregião, o município de Missão Velha é o $8^{\circ}$ município brasileiro na produção de banana do País (IBGE, 2016).

Em 2015, o município de Missão Velha produziu 26,1 mil toneladas de banana, com 1.310 hectares de área colhida, essa produção corresponde a 1,3\% do total da produção nacional (DIÁRIO DO NORDESTE, 2016). Segundo o Diário do Nordeste (2014), a fruticultura irrigada tem se destacado na região do Cariri, e Missão Velha é exemplo disso, o jornal destaca que o aumento das áreas de plantio de banana tem chamado atenção e que grande parte está nas mãos de grandes produtores, que isso incentivou os agricultores a reconhecer o potencial agrícola da região, que hoje possui além de grandes produtores, 126 famílias produtoras (agricultura familiar), essa nova realidade tem gerado renda e melhorado a qualidade de vida da população local.

Além de Missão Velha, a mesorregião Sul Cearense ainda conta outros municípios bastante produtivos, como Farias Brito, Santana do Cariri, Crato, Barbalha, Juazeiro, Barbalha, Porteiras, Milagres, Mauriti, Pena Forte, Barro e Jardim. A Tabela 1 mostra a produção de cada município citado.

Tabela 1. Produção dos Municípios com inviabilidade de geração de energia eólica.

\begin{tabular}{|c|c|c|}
\hline & Área Colhida (ha) & Quantidade Produzida (t) \\
\hline Noroeste Cearense & 11918 & 116874 \\
\hline Coreaú & 47 & 380 \\
\hline Frecheirinha & 25 & 190 \\
\hline Ipu & 31 & 197 \\
\hline Pires Ferreira & 43 & 96 \\
\hline Reriutaba & 376 & 1657 \\
\hline Santa Quitéria & 144 & 707 \\
\hline Sobral & 205 & 1143 \\
\hline Varjota & 853 & 20412 \\
\hline Centro-Sul Cearense & 827 & 19957 \\
\hline Acopiara & 3 & 18 \\
\hline Carius & 109 & 3265 \\
\hline Icó & 140 & 2789 \\
\hline Iguatu & 512 & 13814 \\
\hline Lavras da Mangabeira & 163 & 2075 \\
\hline Várzea Alegre & 152 & 4068 \\
\hline Sul Cearense & 2920 & 59231 \\
\hline Barbalha & 640 & 18400 \\
\hline Barro & 272 & 3868 \\
\hline Crato & 300 & 4800 \\
\hline Farias Brito & 30 & 540 \\
\hline Jardim & 12 & 60 \\
\hline Juazeiro & 30 & 570 \\
\hline Mauriti & 200 & 2806 \\
\hline Milagres & 29 & 782 \\
\hline Missão Velha & 1310 & 26100 \\
\hline Pena Forte & 9 & 198 \\
\hline Porteiras & 158 & 2904 \\
\hline Santana do Cariri & 20 & 180 \\
\hline
\end{tabular}

Fonte: IBGE - PAM (Produção Agrícola Municipal) - 2016.

A mesorregião Norte possui elevado potencial para a geração de energia eólica, onde se destacam os seguintes municípios: Itapipoca,
Uruburetama, Itapajé, Itatira, Palmácia, Redenção, Pacotí, Guaramiranga, Mulungu, Aratuba, Baturité e Capistrano. A mesorregião 
de Jaguaribe também apresenta potencial eólico satisfatório para geração de energia, nessa mesorregião os principais municípios produtores são Aracati, Russas, Jaguaruana, Quixeré, Limoeiro do Norte e São João do Jaguaribe.

A mesorregião Metropolitana também apresenta potencial eólico que favorece a geração de energia, mas os municípios apresentam uma produção de banana mais discreta que as mesorregiões apresentadas anteriormente, nessa mesorregião os municípios com maior produção são Caucaia, Guaiuba, Maranguape e Pacatuba. A mesorregião do Noroeste Cearense apresenta municípios produtores de banana com viabilidade de geração de energia e municípios com viabilidade, entre estes se destacam pela produção os municípios de Viçosa, Tianguá, Ubajara, Ibiapina, São Benedito, Guaraciaba do Norte, Massapê e Acaraú. A Tabela 2 elenca a produção de cada município citado.

Tabela 2. Produção dos Municípios com viabilidade de geração de energia eólica.

\begin{tabular}{|c|c|c|}
\hline & Área Colhida (ha) & Quantidade Produzida (t) \\
\hline Norte Cearense & 44329 & 159050 \\
\hline Aratuba & 1750 & 5250 \\
\hline Baturité & 12430 & 49207 \\
\hline Capistrano & 650 & 2600 \\
\hline Guaramiranga & 250 & 1000 \\
\hline Itapajé & 4712 & 11780 \\
\hline Itapipoca & 2752 & 16694 \\
\hline Itatira & 250 & 500 \\
\hline Mulungu & 1500 & 4500 \\
\hline Pacotí & 2300 & 14950 \\
\hline Palmácia & 1490 & 5960 \\
\hline Redenção & 3025 & 10475 \\
\hline Uruburetama & 3172 & 11261 \\
\hline Jaguaribe & 9368 & 182942 \\
\hline Aracati & 261 & 4000 \\
\hline Jaguaruana & 122 & 2390 \\
\hline Limoeiro & 1720 & 43000 \\
\hline Quixeré & 1173 & 21114 \\
\hline Russas & 1185 & 15150 \\
\hline São João do Jaguaribe & 293 & 6446 \\
\hline Metropolitana & 1768 & 7498 \\
\hline Caucaia & 450 & 2003 \\
\hline Guaiuba & 180 & 528 \\
\hline Maranguape & 126 & 350 \\
\hline Pacatuba & 99 & 639 \\
\hline Noroeste Cearense & 11918 & 116874 \\
\hline Acaraú & 121 & 1442 \\
\hline Guaraciaba & 755 & 6380 \\
\hline Ibiapina & 387 & 4173 \\
\hline Massapê & 100 & 500 \\
\hline Meruoca & 36 & 160 \\
\hline São Benedito & 424 & 3508 \\
\hline Tianguá & 900 & 6300 \\
\hline Ubajara & 350 & 2468 \\
\hline Viçosa & 550 & 3850 \\
\hline
\end{tabular}

Fonte: IBGE - PAM (Produção Agrícola Municipal) - 2016.

Diante das necessidades agronômicas da banana, apresentadas na metodologia, vê-se que as necessidades edafoclimáticas do Ceará atendem a todas as necessidades, exceto a oferta de água, a banana é muito exigente nesse quesito e isso obriga o uso de irrigação para que se obtenha um resultado produtivo satisfatório. Segundo Robinson e Galán Saúco (2010), as condições semiáridas, exigem o uso de irrigação no cultivo de bananeiras, pois a 


\section{ESTUDO DE VIABILIDADE DO USO DE ENERGIA EÓLICA PARA IRRIGAÇÃO DA BANANICULTURA DO CEARÁ}

demanda evaporativa, frequentemente, excede a capacidade da bananeira para extrair água do solo, o que provoca perda de turgor e murcha temporária. $\mathrm{Na}$ Figura 8A observa-se que várias áreas produtivas de banana coincidem com os perímetros irrigados do Ceará, também é possível observar na Figura 8B a hidrografia do Estado e avaliar os reservatórios e rios que permitam a aquisição de água para irrigação.
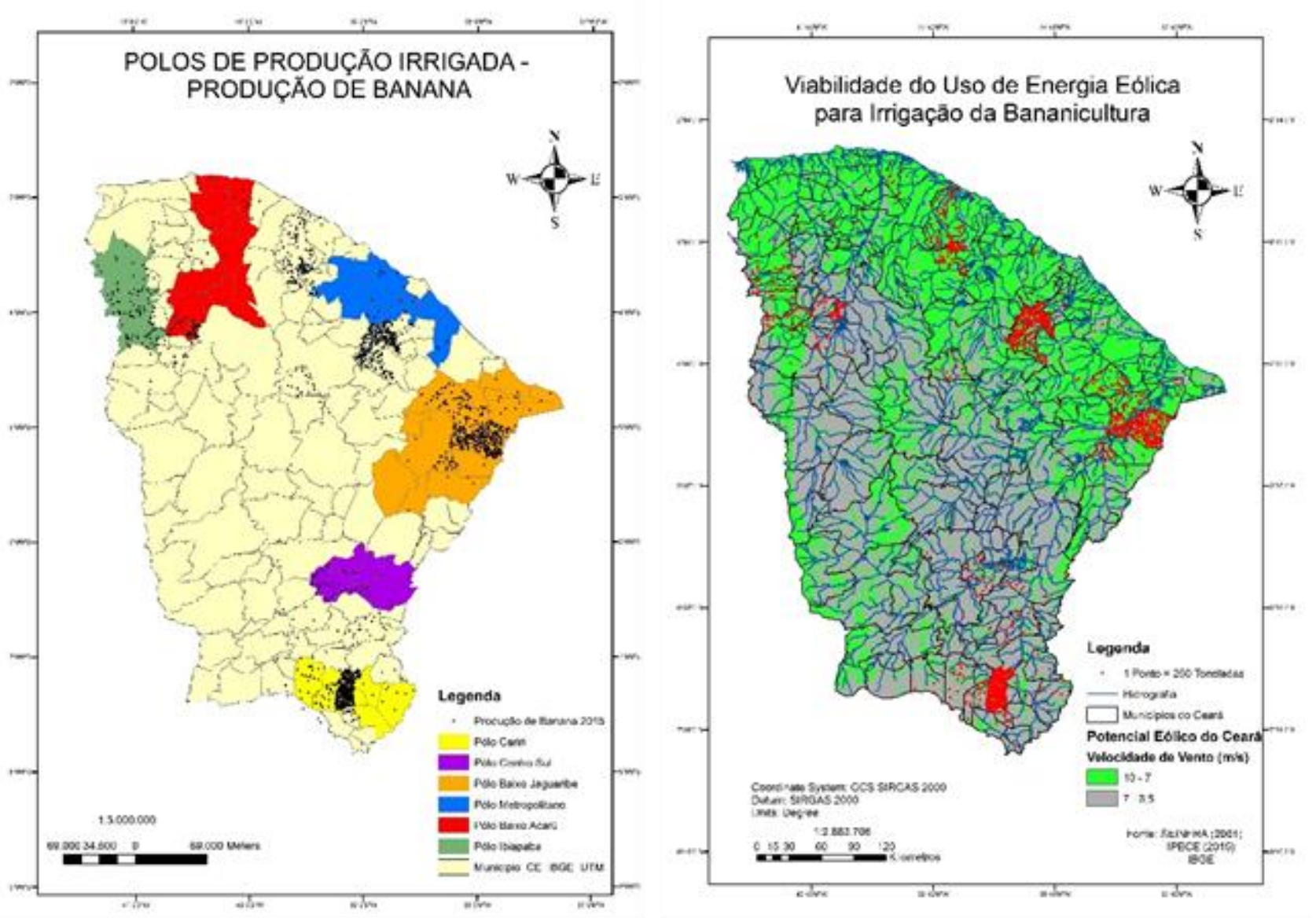

Figura 8. A - Municípios produtores de banana e perímetros irrigados do Ceará; B - Viabilidade do uso de energia eólica para irrigação da Bananicultura do Ceará.

As Limitações da bananeira a ventos fortes não impedem o uso da energia eólica para gerar energia elétrica para os sistemas de irrigação, pois as velocidades de vento mostradas aqui nessa pesquisa, são de dados anemométricos a $50 \mathrm{~m}$ do solo, à medida que essa altura é reduzida, a velocidade do vento também reduz, por tanto é importante ressaltar ainda que os portes das bananeiras são em média ente 1,5 a $3 \mathrm{~m}$.

A energia eólica está sendo apresentada nesse estudo, como uma fonte de energia alternativa a energia elétrica oferecida pela concessionária de energia do Estado, visando reduzir o custo de distribuição de energia da sede na unidade agrícola até o campo (onde o plantio de banana está localizado). Porém existe o custo dos rotores que captam o vento e tornam possível a geração de energia eólica, para solucionar esse impasse, existe uma linda de crédito do governo chamada PRONAF Eco, voltada exclusivamente para a agricultura familiar, visando financiar projetos na utilização de tecnologias de energia renovável, com juros de 2,5\% ao ano, o BNDES financia até $100 \%$ do valor dos itens financiáveis, os valores podem variar de 88 mil reais por beneficiário e 165 mil por ano agrícola, os prazos são de 10 anos, com 3 anos de carência, a mesma unidade familiar de produção pode contratar até dois financiamentos consecutivos (BNDES, 2018).

A geração distribuída de energia, permite que o cliente, instalem em suas propriedades 
pequenas usinas geradoras de energia renovável para consumo próprio, quando a unidade excede na produção, a energia gerada é inserida na rede da concessionária de energia, e contabilizada pelo medidor bidirecional que registra a energia que é consumida e a que é gerada, no caso de uma geração de energia maior que a consumida o cliente recebe um crédito de energia que pode ser utilizado na mesma unidade consumidora ou em outra unidade, conforme o modelo do sistema de compensação (ENEL, 2018).

Optar pelo uso de energias renováveis, requer antes de tudo conhecer bem os recursos naturais e potencialidades do local, essa pesquisa mostra através do uso de geoprocessamento que permite um estudo remoto, ou seja, sem necessidade de visita presenciais ao local a ser estudado, os municípios produtores de banana que possuem viabilidade para o uso de energia eólica e os municípios que possuem inviabilidade do uso, para esses últimos, sugere-se o estudo da viabilidade de uso de outras fontes de energias renováveis, tais como solar fotovoltaica e biogás (biocombustível obtido a partir da fermentação de matéria orgânica).

Este estudo permite que através das coordenadas geográficas da propriedade rural o proprietário possa ter um estudo preliminar da viabilidade e potencialidade do local para geração de energia eólica e se existe ou não disponibilidade de água para irrigação, avaliando a existência de reservatórios, rios perenes e canais de irrigação.

\section{CONCLUSÕES}

Os mapas gerados permitiram avaliar a potencialidade dos municípios produtores de banana do estado Ceará para gerar energia eólica, com o objetivo de utilizá-la para atender a demanda energética dos sistemas de irrigação.

Obteve-se como resultado, que os municípios com uma produção mais expressiva, dentre os 184 municípios do estado, 31 municípios apresentaram viabilidade para a geração de energia eólica e 26 municípios não apresentam potencialidade para geração de energia eólica. Dos municípios com inviabilidade de geração de energia eólica, aqueles que apresentaram maior expressividade em sua produção foram: Varjota (região Noroeste), Iguatu (região Centro-Sul) e Missão Velha (região Sul). Já nos municípios com viabilidade de geração de energia eólica, aqueles que apresentaram maior expressividade em sua produção foram: Baturité (região Norte), Limoeiro do Norte (Região do Jaguaribe), Caucaia (Região Metropolitana) e Guaraciaba (região Noroeste).

O Estado do Ceará tem crescido muito nas últimas décadas no setor eólico, aumentando cada vez mais a geração de energia eólica. Já existe no mercado torres de pequeno porte, sendo mais acessível ao pequeno produtor, além de reduzir custos na produtividade da bananicultura, a produção de energia eólica não agride o meio ambiente.

É possível um avanço no trabalho a partir da publicação do novo mapa de potencial eólico anual do Atlas de potencial eólico do estado do Ceará, no qual está programado para sua publicação neste ano (2020).

\section{AGRADECIMENTOS}

Ao Projeto CNPq/ Nexus I Proc. $n^{\circ}$ 441489/2017-6, Ao Projeto PRINT/ CAPES Proc. n. 88887.312019/2018-00 e a Fundação Cearense de Apoio ao Desenvolvimento Científico e Tecnológico.

\section{REFERÊNCIAS BIBLIOGRÁFICAS}

ABEEOLICA (Associação Brasileir a de Energia Eólica). Boletim Anual de Geração Eólica. 2018. Disponível em: <http: //abeeolica.org.br /wp-content/uploads/2019/05/Boletim-

Anual_2018.pdf >. Acesso em: 01 jun. 2018

$\begin{array}{lccc}\text { ANEEL } & \text { (Agência } & \text { Nacional } & \text { de } \\ \text { Energia } & \text { Elétrica), } & \text { Banco } & \text { de }\end{array}$


Informações de Geração. 2017. Disponível em: $<\mathrm{http}: / / \mathrm{www} 2$. aneel.gov.br/aplicacoes/capacid adebrasil/capacidadebrasil>. Acesso em: 01 jun. 2018.

ANEEL (Agência Nacional de Energia Elétrica), Atlas de Energia Elétrica. 2005. Disponível em:

http://www2.aneel.gov.br/aplicacoes/atlas/dow nload.htm>. Acesso em: 01 jun. 2018

BNDES - Banco Nacional de Desenvolvimento. Pronaf Eco. 2018. Disponível em: < https://www.bndes.gov.br/wps/portal/site/hom e/financiamento/produto/pronaf-eco>. Acesso em: 01 jun. 2018

BRASIL. Ministério da Agricultura Pecuária e Abastecimento. Secretaria de Defesa Agropecuária. ALERTA

QUARENTENÁRIO: Fusarium oxysporum f.sp. cubense, raça 4 tropical (R4T) fusariose da bananeiraetaria de Defesa Agropecuária. 2018. Disponível em: $<\mathrm{http} / / /$ www.agricultura.gov.br/assuntos/sanid ade-animal-e-vegetal/sanidade-

vegetal/arquivosdpcp/CARTILHAAPROVADAparapaginaDS V.zip.pdf>. Acesso em: 14 set. 2019.

\section{DIARIO DO NORDESTE. Cultivo de Frutas} em Áreas Irrigadas Mostra sua Força. 2014. Disponível em:< http://diariodonordeste.verdesmares.com.br/su plementos/cariri-regional/cultivo-de-frutasem-area-irrigada-mostra-sua-forca-1.813268> . Acesso em: 01 jun. 2018

\section{DIARIO DO NORDESTE. Missão Velha é $\mathbf{8}^{\mathbf{0}}$} maior produtor de banana. 2016. Disponível em:

$<\mathrm{http}: / /$ diariodonordeste.verdesmares.com.br/c adernos/negocios/missao-velha-e-8-maiorprodutor-de-banana-1.1622523>. Acesso em: 01 jun. 2018

EMBRAPA - Empresa Brasileira de Pesquisa Agropecuária. Características da Espécie.
2018. Disponível em: < http://www.agencia.cnptia.embrapa.br/Agenci a40/AG01/arvore/AG01_13_41020068054.ht ml>. Acesso em: 01 jun. 2018

ENEL. Geração Distribuída. 2018. Disponível em: https://www.bndes.gov.br/wps/portal/site/hom e/financiamento/produto/pronaf-eco>. Acesso em: 01 jun. 2018

FAO - Food And Agriculture Organization. Banana. 2018. Disponível em: < http://www.fao.org/land-water/databases-andsoftware/crop-information/banana/en/>.

Acesso em: 01 jun. 2018

GWEC (Global Wind Energy Council). Global Wind Report: Annual Market Update 2016, Global Wind Energy Council, Brussels, 2017.

IBGE - Instituto Brasileiro de Geografia e Estatística. Cidades: Ceará. 2018. Disponível em:< https://cidades.ibge.gov.br/brasil/ce>. Acesso em: 01 jun. 2018

IBGE - Instituto Brasileiro de Geografia e Estatística. Produção Agrícola por Município - PAM. 2017. Disponível em:< https://www.ibge.gov.br/estatisticasnovoportal/economicas/agricultura-epecuaria/9117-producao-agricola-municipalculturas-temporarias-eermanentes.html?=\&t=resultados >. Acesso em: 01 jun. 2018

IBGE - Instituto Brasileiro de Geografia e Estatística. Geociências. 2018. Disponível em:<ftp://geoftp.ibge.gov.br/organizacao_do_t erritorio/malhas_territoriais/malhas_municipai s/municipio_2015/UFs/>. Acesso em: 01 jun. 2018

IPECE - Instituto de Pesquisa e Estratégia Econômica do Ceará. Mapas Aspectos Econômicos. 2015. Disponível em: < http://www2.ipece.ce.gov.br/atlas/capitulo5/51 /512/522.htm>. Acesso em: 01 jun. 2018. 
MME - Ministério de Minas e Energia. Impactos do Programa Luz para Todos. 2013. Disponível em:< https://www.mme.gov.br/luzparatodos/downlo ads/pesquisa_de_satisfacao_2013.pdf >.

Acesso em: 01 jun. 2018

MME - Ministério de Minas e Energia. O Programa Luz para Todos. 2018. Disponível em:<https://www.mme.gov.br/luzparatodos/as p/>. Acesso em: 01 jun. 2018

PAGANO, M. C.; ZANDAVALLI, R. B.; ARAÚJO. F. S. Biodiversity of arbuscular mycorrhizas in three vegetational types from the semiarid of Ceará State, Brazil. Applied Soil Ecology, v. 63, p. 37-46, 2013. Disponível em: $<$ https://ac.els-

cdn.com/S0929139313000619/1-s2.0-

S0929139313000619-

main.pdf?_tid=e4af9da6-7d5d-4154-9c57

e2a3a46d53a\&acdnat $=1528118869 \_8 a 1 c e 50 d$ 24549c4cae9dd34309639f4f >. Acesso em: 01 jun. 2018
ROBINSON, J. C.; GALÁN SAÚCO, V. Bananas and plantains. 2nd ed. Oxford: $C A B$ International, 2010. 311p. (Crop production science in horticulturae series, 19).

SANHES, Ieda Del'arco. Sensoriamento Remoto Aplicado à Agricultura. 2016. INPE: Instituto de Pesquisas Espaciais. Disponível em: $\quad<$ http://www.dsr.inpe.br/vcsr/files/6Sensoriamento_Remoto_Aplicado_a_Agricult ura.pdf>. Acesso em: 14 set. 2019.

SEEG Emissões dos Setores de energia, processos industriais e uso de produtos. 2017. Disponível em: $<$ http://seeg.eco.br/wpcontent/uploads/2017/09/Relatorios-Seeg-

2017-Energia-final.pdf>. Acesso em: 01 jun. 2018

SEINRA - Secretária de Infraestrutura do Ceará. Mapa do Potencial Eólico do Estado do Ceará. 2001. Disponível em: <http://www.seinfra.ce.gov.br/downloads/Atla s.zip>. Acesso em: 01 jun. 2018. 